\title{
A UTILIZAÇÃO DE RECURSOS MIDIÁTICOS NO PROCESSO DE ENSINO/APRENDIZAGEM A DISTÂNCIA
}

\author{
THE USE OF MIDI RESOURCES IN THE DISTANCE TEACHING / LEARNING PROCESS
}

\author{
Aldeci dos Santos \\ Universidade Federal de Sergipe, SE, Basil. E-mail: aldeci26@hotmail.com \\ https://orcid.org/0000-0002-8468-2760
}

DOI: https://doi.org/10.46550/amormundi.v2i1.59

Recebido em: 10.01.2021

Aceito em: 28.01.2021

\begin{abstract}
Resumo: A educação à distância $(\mathrm{EAD})$ pode e tem sido realizada por diversos meios, seja rádio, correio, telefone, televisão, dentre outros. $\mathrm{O}$ video faz parte deste processo haja vista que o seu uso está cada vez mais presente em nosso dia a dia em vários lugares. Desta forma faz-se necessário à sua grande relevância no campo educacional como meio de informação e comunicação em sala de aula. O uso do vídeo na educação vem dinamizar este processo, deixando as aulas mais estimulantes e significativas, possibilitando ao alunato uma maior atração e concretização mais eficaz dos conteúdos em diversas áreas do conhecimento. Desta forma, o presente artigo visa analisar a utilização do vídeo no processo de ensino/aprendizagem, no que se refere à modalidade EAD.
\end{abstract}

Palavras-chave: Educação à distância, ensino/aprendizagem, vídeo.

Abstract: The distance learning $(O D L)$ can and has been done by various means, whether radio, mail, telephone, television, among others. The video is part of this process given that their use is increasingly present in our daily lives in many places. Thus it is necessary to its great relevance in education as a means of information and communication in the classroom. The use of video in education comes streamline this process, making lessons more exciting and meaningful, allowing the greater attraction alunato and more effective implementation of content in different areas of knowledge. Thus, this article aims to analyze the use of video in the teaching I learning process, in relation to the ODL mode.

Keywords: Distance education, teaching / learning, video.

\section{Introdução}

ducação, do latim "educere", significa extrair, tirar, desenvolver. Consiste na formação
de caráter; é um processo vital, para o qual concorrem forças naturais e espirituais, conjugadas pela ação consciente do educador e pela vontade livre do educando (BRANDÃO, 1982). Segundo Maritain (cit. in BRANDÃO, 1982, p. 65), “... o objetivo da educação é guiar o homem no desenvolvimento dinâmico, no curso do qual se constituirá como pessoa humana, dotada das armas do conhecimento, do poder de julgar e das virtudes morais”. 
De acordo com a atual Constituição Brasileira, a educação é um direito de todos os cidadáos e a escola, como instituição social, está inserida numa certa realidade social que a influência e na qual exerce influência de valores na ciência, na política e na cultura (RODRIGUES, 1998).

Mesmo em comunidades onde não há um sistema centralizado de governo, escolas e ensino especializado formal, a educação e a aprendizagem estão presentes. Assim sendo, a Educação é vista como promoção do desenvolvimento de todas as dimensões da natureza humana.

Partindo desse princípio pode-se afirmar que a Educação a distância é uma modalidade de educação que integra os cidadãos em uma sociedade plural e democrática, como podemos verificar na citação de Letwin (1997: p. 9):

na virtualidade tais encontros são possíveis. Talvez tenhamos que dar outro nome para a educaçáo a distância, visto que hoje ela já não se define pela distância. O que seguramente não vamos mudar é sua definição de educação e a busca de produzir um bom ensino, do mesmo modo que em qualquer outra proposta educativa.

Educação à distância, segundo Moore (1973 apud BELLONI,2006 p. 25), pode ser definida como a família de métodos instrucionais nos quais os comportamentos de ensino são executados em separado dos comportamentos de aprendizagem, incluindo aqueles que numa situação presencial (contígua) seriam desempenhados na presença do aprendente de modo que a comunicaçáo entre o professor e o aprendente deve ser facilitada por dispositivos impressos, eletrônicos, mecânicos e outros.

A educação a distância está modificando todas as formas de ensino e aprendizagem, inclusive as presenciais, que estáo utilizando cada vez mais metodologias semipresenciais, flexibilizando assim a necessidade de presença física e reorganizando os espaços e tempos.

Através de chats, fóruns e mensagens dá-se um aprendizado grandioso, visto que estes promovem a troca de ideias, informaçóes entre professor/aluno, professor/professor, aluno/ aluno. Sendo assim, evidencia-se um crescimento nos diversos campos que abrange a Educação a Distância, além de uma rápida evolução das redes e mobilidade tecnológica, como também a abrangência dos sistemas de comunicação digitais com seus modelos distintos.

O uso da Tecnologia faz parte deste processo, sendo de fundamental importância, para a educação a distância, contribuindo na área educacional, pois em um mundo globalizado, o uso da Tecnologia é de suma importância nos projetos pedagógicos, haja vista que o seu uso está cada vez mais presente em nosso dia a dia em vários lugares. Podemos citar como exemplo as mídias, que surgem como mediatizada, assumindo papel de informação e comunicação. No espaço escolar sua contribuição é relevante a ponto de proporcionar uma inter-relação necessária para formação de uma visão holística da presente problemática.

Desta forma faz-se necessário à sua grande relevância no campo educacional como meio de informação e comunicação em sala de aula. $\mathrm{O}$ uso do vídeo na educação vem dinamizar este processo, deixando as aulas mais estimulantes e significativas, possibilitando ao alunato uma maior atração e concretização mais eficaz dos conteúdos em diversas áreas do conhecimento. Desta forma, o presente artigo objetiva analisar a contribuição do vídeo no processo de ensino/ aprendizagem, no que se refere à modalidade EAD. 
2 Diagnóstico sobre as metodologias de ensino no Brasil e o seu papel na dinamizaçáo das aulas

Até a promulgação da Lei de Diretrizes e Bases da Educação (LDB), lei 4.024 de 1961, o cenário escolar era dominado pelo ensino tradicional, onde cabia ao professor a transmissão de conhecimentos acumulados, por meio de aulas expositivas, e aos alunos, a absorção dos conteúdos e reprodução das informaçôes (BRASIL, 1998). Atualmente, a maioria dessas aulas ainda continua baseada na mera transmissão de informaçôes, tendo como principal recurso o livro didático e sua transcrição na lousa, tornando assim as aulas desinteressantes e pouco compreensíveis, fazendo com que os alunos sejam meros expectadores (DELIZOICOV; ANGOTI; PERNAMBUCO, 2003).

Diante dessa situação, Lopes (2001) destaca que o professor deve ser criativo, de espírito transformador, deve sempre tentar inovar sua prática. Um dos caminhos para tal fim seria dinamizar as atividades desenvolvidas em sala de aula. $\mathrm{O}$ que se percebe em algumas salas de aula, porém, é a utilização única do livro didático, prevalecendo como principal instrumento de trabalho do professor em sua prática docente.

Apesar de haver outros recursos serem de fundamental importância na aprendizagem, esta, na maioria das vezes, não é trabalhada pelos docentes em suas aulas, pois apesar destes inovarem suas técnicas e a maneira como lecionam, o método tradicional continua sendo utilizado, tendo como material auxiliar o livro didático. Segundo Franco (1982), os livros didáticos se destinam a instruir, coadjuvando o trabalho do professor numa área qualquer do conhecimento humano, tendo como função apresentar conteúdos das matérias curriculares.

Por isso, cabe aos professores selecionar e utilizar outros materiais e instrumentos mais atrativos para os alunos, como: livros paradidáticos, jogos, revistas, suplementos de jornais, vídeos, CD-ROM, entre outros, a fim de que estes obtenham uma melhor aprendizagem.

\section{Ambientes virtuais de aprendizagem (ava) e sua contribuiçáo para o ensino à distância}

Ambientes virtuais de aprendizagem são sistemas computacionais disponíveis na internet, destinados ao suporte de atividades mediadas pelas tecnologias de informação e comunicação. Permitem múltiplas mídias, linguagem e recursos, apresentar informaçóes de maneira e objetos de conhecimento, elaborar e socializar produçôes tendo em vista atingir determinados objetivos.

As atividades se desenvolvem no tempo, ritmo trabalho e espaço em que cada participante se localiza, de acordo com uma intencionalidade explícita e um planejamento prévio denominado design educacional. Os recursos dos ambientes virtuais de aprendizagem são basicamente os mesmos existentes na internet (Correio, Fórum, bate-papo, conferência, banco de recursos, etc.), com a vantagem de propiciar a gestão da informação segundo critérios preestabelecidos de organização definidos de acordo com as características de cada software. Possuem bancos de informaçôes representadas em diferentes mídias (textos, imagens, vídeos hipertextos), e interligadas em conexóes constituídas de links internos ou externos ao sistema.

$\mathrm{O}$ gerenciamento desses ambientes diz respeito a diferentes aspectos, destacando-se a gesto das estratégias de comunicação e mobilização dos participantes, a gestão da participação dos alunos por meio de registro das produções, interaçóes e caminhos percorrido, a gestão do 
apoio e orientação da avaliação. Os ambientes virtuais de aprendizagem podem se empregados como suporte para sistema de educação a distância realizados exclusivamente on-line, para apoio às atividades presenciais de sala de aula, permitindo expandir as interaçôes da aula para além do espaço, tempo de encontro face a face ou para suporte de formação semipresencial nas quais o ambiente virtual poderá ser utilizado tanto nas açôes presenciais como nas atividades à distância.

De acordo com Castells, (1999), novos processos criativos podem ser potencializados fluxos sociotécnico de ambientes virtuais de aprendizagem que utilizam o digital como suporte a exemplo, o ciberespaço. A educação on-line, a educação à distância e-learning são termos usuais da área, porém não são congruentes entre si.

A educação a distância pode se realizar pelo uso de diferentes meios como (correspondência postal, ou eletrônica, rádio, televisão, telefone, fax, vídeo, computador, internet etc.), técnicas que possibilitam a comunicação e abordagens educacionais, baseia-se tanto na noção de distância física entre o aluno e o professor como n flexibilidade de tempo e na localidade do aluno em qualquer espaço. A educação on-line é uma modalidade de educação a distância realizada via internet, cuja comunicação ocorre de forma sincrônica ou assincrônicas. Tanto pode utilizar a internet para distribuir rapidamente as informaçóes como pode fazer uso de interatividade propiciada pela internet para concretizar a interação entre pessoas, cuja comunicação pode se dar de acordo com modalidades comunicativas, a saber.

A comunicação todos-todos, ou dito de outra forma, comunicação entre uma e outra pessoa, como é o caso da comunicação via e-mail, que pode ter uma mensagem enviada para muitas pessoas desde que exista uma lista específica para tal fim, mas sua concepção é a mesma da correspondência tradicional, portanto, existe uma pessoa que remete a informação e outra que recebe; comunicação de um para muitos, ou seja, de uma para muitas pessoas, como ocorre nos fóruns de discussão, nos quais existe um mediador e todos que têm acesso ao fórum, enxergam as intervençôes e fazem suas intervençóes; Observação, a comunicação de muitas pessoas, ou comunicação estelar, que pode ocorrer na construção colaborativa de um site ou na criação de um grupo virtual, como é o caso das comunicaçóes colaborativas em que todos participam da criação e desenvolvimento da própria comunicação e respectivas de produçôes.

$\mathrm{Na}$ EAD em meio digital, pode-se observar que existe um foco central em determinado aspecto, diretamente relacionado com a abordagem educacional implícita, o qual pode ser; $\mathrm{O}$ material instrucional disponibilizado, cuja abordagem está centrada na informação fornecida por um tutorial ou livro eletrônico hipermediáticos. Essa abordagem se assemelha á autoinstrução e distribuição de materiais, chegando a dispensar a figura do professor.

O docente, considerado o centro do processo educacional, o que indica a abordagem centrada na instruçáo fornecida pelo professor, que recebe distintas denominaçóes de acordo com a proposta do curso. O aluno, que aprende por si mesmo, em contato com os objetos disponibilizados no ambiente, realizando as atividades propostas a seu tempo e de seu espaço. As relaçóes que podem se estabelecer entre todos os participantes evidenciado um processo educacional colaborativo no qual todos se comunicam com todos e podem produzir conhecimento, como ocorre nas comunidades virtuais colaborativas.

Em um mesmo curso á distância, conforme as características da atividade podem existir alternância entre focos, sendo possível lançar mão de diferentes meios e recursos, tais como hipertextos veiculados CD-ROM, distribuição de material impresso via correios, vídeos, 
teleconferência, etc. Também denominado e- learning híbrido, pode englobar autoformação assincrônicas, interações sincrônicas em ambientes virtuais, encontros ou aulas e conferências presenciais, outras dinâmicas usuais de aprendizagem e diversos meios de suporte á formação, tanto digitais como outros mais convencionais.

A distância geográfica de múltiplas mídias são características inerentes á educação à distância, mas não são suficientes para definirem a concepção educacional. A par disso, o ótico presente na regulamentação do artigo 80 da LDB, do decreto no 2.494 de 10/02/98, indica como características da educação a distância a autoaprendizagem mediada por recursos didáticos, sem salientar o papel do aluno e do professor, bem como as respectivas interaçôes e intencionalidades implícitas em todo ato pedagógico voltado ao desenvolvimento de competência, habilidades e atitudes.

Entretanto, mesmo com o uso de recursos das TICs, observa-se com maior frequência a ocorrência de programas de EAD centrados na disponibilidade de materiais didáticos textuais ou hipertextuais, cabendo ao aprendiz navegar pelos materiais, realizar as atividades propostas e dar as respostas, muitas vezes isolado, sem contato com o formador ou com os demais participantes do programa. Nesse caso, o exercício da autonomia pelo aprendiz incita-lhe a tomada de decisão sobre os caminhos a seguir na exploração dos conteúdos apresentados e a disciplina nos horários de estudos. Os recursos da TIC podem ser empregados para controlar os caminhos percorridos pelo aprendiz, automatizar o fornecimento de respostas ás suas atividades e o feedback em relação ao seu desempenho.

Diante disso, Prado e Valente (2002) ressalta que participar de um ambiente digital se aproxima do estar junto virtual, uma vez que atuar nesse ambiente significa expressar pensamentos, tomar decisóes, dialoga trocar informaçóes e experiências e produzir conhecimento.

Aprender a planejar, desenvolver açôes, selecionar e enviar informaçôes, estabelecer conexôes, refletir sobre o processo em desenvolvimento em conjunto com os pares, desenvolver a Inter aprendizagem, a competência em resolver problemas em grupo e a autonomia em relação à busca de fazer compreender.

Com o uso de ambientes digitais de aprendizagem, redefine-se o papel do professor que finalmente pode compreender a importância de ser parceiro de seus alunos e escritor de suas ideias e propostas, aquele que navega junto com os alunos, apontando as possibilidades dos novos caminhos sem a preocupação de ter experimentado passar por eles algum dia.

\section{A importância das novas tecnologias na educaçáo à distância}

O advento das tecnologias de informação e comunicação (TIC) reavivou as práticas de EAD devido á flexibilidade do tempo, quebra de barreiras espaciais, emissão e recebimento instantâneo de materiais, o que permite realizar tanto as tradicionais formas mecanicistas de transmitir conteúdos, agora digitalizados e hipermediáticos, como explorar o potencial de interatividade das TIC e desenvolver atividades á distância com base na interação e na produção de conhecimento.

Quando os recursos das redes telemáticas são utilizados da mesma forma que a sala de aula presencial, acontece a virtualização da sala de aula, que procura transferir para o meio virtual o paradigma do espaço - tempo de aula e da comunicação bidirecional entre professor e 
alunos, contudo, é preciso compreender que não basta colocar os alunos em ambientes digitais para que ocorram interaçóes significativas em torno de temáticas coerentes com as intenções das atividades em realização, nem tampouco se pode admitir que o acesso a hipertextos e recursos multimediáticos de conta da complexidade dos processos educacionais.

\section{A contribuiçáo do vídeo no processo educativo}

Podemos citar meios de comunicação e informação existentes na atualidade, a exemplo do telefone, a televisão, o rádio, o jornal e a internet. Através dessas tecnologias é possível que haja, de forma cada vez mais eficiente, uma comunicação entre pessoas dispersas geograficamente no menor espaço de tempo.

De acordo com Moran (2000), Na sociedade da informação todos estamos reaprendendo a conhecer, a comunicar-nos, a ensinar e a aprender; a integrar o humano e o tecnológico; a integrar o individual, o grupal e o social. Uma mudança qualitativa no processo de ensino/ aprendizagem acontece quando conseguimos integrar dentro de uma visão inovadora todas as tecnologias: as telemáticas, as audiovisuais, as textuais, as orais, musicais, lúdicas e corporais. Passamos muito rapidamente do livro para a televisão e vídeo e destes para o computador e a Internet, sem aprender e explorar todas as possibilidades de cada meio.

Desta forma, é de fundamental importância salientar a importância do vídeo no processo educacional, pois juntamente com a TV, ambos podem transmitir informaçóes, linguagens, privilegiando alguns valores e contribuindo com metodologias e potencialidades no que se refere a sua utilização na educação. Moran (2000), ainda não foram exploradas todas as possibilidades dessas mídias no contexto educacional.

Moran (1995) discorre sobre a importância na utilização de vídeos e de TV na educação, onde estes auxiliam o despertar da curiosidade, permite compor cenários desconhecidos pelos alunos, permite simulaçôes da realidade, reproduz entrevistas, depoimentos, documentários, auxilia no desenvolvimento da construçáo do conhecimento coletivo pela análise em grupo e o desenvolvimento do senso crítico.

\section{0 vídeo como instrumento de ensino/aprendizagem em EAD}

Existem cursos a distância que oferece o video como ferramenta para seus alunos como forma de aula, em que o professor da disciplina apresenta a matéria de maneira clara e objetiva. Para isso os docentes elaboram vídeos-aula, onde professores e coordenação se reúnem para definir a temática a ser trabalhada, objetivos e conteúdos a serem tratados.

Além disso, o professor e a coordenação devem ter um roteiro prévio do que deverá ser o vídeo, e finalmente o roteiro acabado, que é o texto escrito de tudo o que se verá e ouvirá na tela. É importante ressaltar que a avaliaçáo de um vídeo educativo não se faz da análise apenas do vídeo em si, mas o uso educativo que dele se faz. Dessa forma, o vídeo deve ser acompanhado de um guia que ofereça sugestóes e orientação para maior exploração educativa.

Pode-se citar como exemplo a webconferência, que é uma forma de utilização do video na educação a distância, pois consiste na geração de palestras via internet, permitindo difundir informaçóes a diversos pontos nos pais e no mundo. Essa ferramenta de ensino, de acordo 
com Santos \& Nascimento (2011), aproxima-se de uma situação convencional da sala de aula, porque possibilita a conversa em duas vias, permitindo que o processo de ensino e aprendizagem ocorra em tempo real (on line) e possa ser interativo entre pessoas que podem se ver e ouvir simultaneamente.

Cruz e Moraes (1997) enumeram as vantagens e desvantagens do uso da webconferência na educação, considerando o atual parâmetro tecnológico. Para os autores, as vantagens seriam: a) a transição mais gradual dos métodos de ensino presenciais; b) o espaço colaborativo para socialização e aprendizado em grupo; c) a seleção e o planejamento de cursos interativos para classes pequenas ou menos interativo para audiências maiores; d) escolha dos meios de transmissão de acordo com a possibilidade, disponibilidade e demanda.

Entre as desvantagens desse gênero, estariam, conforme Cruz e Moraes (1998), a) a baixa qualidade de som e imagem, em alguns casos; b) desconhecimento do potencial.

Nesse sentido, Demo (1998) faz uma critica quanto à questão das elaboraçôes de aulas na modalidade EAD, ou seja, lança mão de aulas mais agradáveis, porque suportadas por tecnologias (vídeo, televisão, teleconferência, ambientes virtuais), mas não ultrapassa o contexto de aula reprodutiva, em que os estudantes são telespectadores passivos e os materiais didáticos não favorecem a aprendizagem na ausência física do professor.

\section{Vídeo conferência: possibilidades e desafios no sistema EAD}

A videoconferência é definida por Oliveira (1996) como um conjunto de facilidades de telecomunicaçóes que permite aos participantes, em duas ou mais localidades distintas, estabelecer uma comunicaçáo bidirecional mediante dispositivos eletrônicos de comunicaçáo, enquanto compartilham, simultaneamente, seus espaços acústicos e visuais, tendo a impressão de estarem todos em um único ambiente.

A videoconferência é uma das melhores ferramentas de abordagem síncrona, pois possibilita o uso de imagem e som em tempo real e é a única que possibilita a explorar a linguagem corporal, a qual é responsável por $80 \%$ das impressões do indivíduo durante uma interação (Musey apud Fischer, 2000). Entretanto, este sistema ainda não pôde se tornar uma realidade popular devido a seu alto custo e à falta de uma infraestrutura de telecomunicaçôes adequada (CARDOSO NETO, 2001).

A videoconferência pode ser apresentada por intermédio das salas de videoconferência ou por meio do computador, cujas conexóes podem ou não ser realizadas pela Internet.

Essas salas são formadas por auditórios equipados com TV's, câmeras de vídeo e consoles de controle. As soluçôes por computador são compostas por modem, placa processadora de som e imagem, uma pequena câmera e um microfone, além do software para videoconferência (CARDOSO NETO, 2001). Esta solução apesar de mais barata e acessível, possui mais limitaçôes, principalmente devido à baixa largura de banda disponível para transmissão de imagem e som via Internet.

De acordo com Sacerdote, (2010), muitas vezes, os que optam por utilizar videoconferência via Internet são obrigados a limitar o uso dos recursos disponíveis, tais como utilizar somente o áudio, sem imagens, ou estabelecer mecanismos de controle, tai como, só o professor transmite imagens e os alunos transmitem apenas áudio. Muitas outras estratégias podem ser adotadas 
para viabilizar o seu uso enquanto náo se dispóe de infraestrutura mais adequada para seu funcionamento.

Os sistemas de videoconferência dispóem de outras ferramentas que facilitam a interação entre os participantes, fazendo com que se tornem ambientes mais completos e interativos. Com este intuito, as salas de videoconferência também dispóem de computadores, além de outros equipamentos como as câmeras digitalizadoras de documentos, onde um documento colocado sobre ela pode ser visualizado por todos os participantes da conferência (SACERDOTE, 2010).

Podem ser apontados como vantagens da videoconferência em relação ao ensino presencial (CARNEIRO, 2001, FISCHER, 2000):

- aumento da motivação dos alunos;

- amplia a capacidade de comunicaçáo e apresentaçáo;

- agilidade e aumento da produtividade, pois permite maior interaçáo entre os participantes;

- economia de recursos, com a redução dos gastos com viagens;

- economia de tempo, evitando o deslocamento físico para um local especial;

- comodidade de estar em mais de um lugar ao mesmo tempo, pois permite a comunicação simultânea entre pessoas distantes umas das outras;

- resolução parcial de problemas de planejamento e agendamento de encontros, aulas ou reunióes, pois não é necessário deslocamento pelos participantes, resultando em praticidade;

- mais um recurso de pesquisa, já que a reunião pode ser gravada e disponibilizada posteriormente;

- visualizaçáo de documentos e alteraçáo pelos integrantes do diálogo em tempo real;

- compartilhamento de aplicaçóes;

- compartilhamento de informaçóes (transferência de arquivos).

$\mathrm{Na}$ Internet, a videoconferência traz ao modelo de $\mathrm{EAD}$ alguns avanços relacionados à táo criticada impessoalidade existente nas demais ferramentas. Ela permite estabelecer um contato visual entre os alunos e professores, deixando este de ser um mero referencial simbólico que faz contato por cartas eletrônicas para desenvolver a personificação dos indivíduos envolvidos na interação. É claro, como já foi dito, existem limitaçôes tecnológicas e estruturais para um bom funcionamento da Videoconferência (SACERDOTE, 2010).

Ainda, de acordo com Sacerdote (2010), se não forem tomados os cuidados necessários, pode se tornar em um instrumento de desmotivação do aluno, visto que tentará falar com o professor e apenas verá uma imagem intercalada por uma sequência de outras imagens que apenas sugerem a ocorrência de algum movimento e sons que de tấo interrompidos se torna impossível produzir um significado compreensível.

Alguns softwares para videoconferência via Internet já estão disponíveis para uso, e são geralmente baseados em uma interface que apresenta as imagens daqueles que estáo conectados no momento. A maioria disponibiliza ainda outras ferramentas adicionais como um chat (bate-papo) para a interação via texto. Este recurso é fundamental para superar obstáculos de comunicaçáo, substituindo parte do que seria dito, em áudio, por textos. 


\section{Conclusão}

Face ao exposto, são notórias as inúmeras contribuições do vídeo, pois beneficia não só o desenvolvimento da percepção do discente através de imagens, textos, sons, movimentos, cores, cenários além de relaçôes espaciais, como também a interação com as tecnologias, mas também torna possível que se utilizem elementos da cultura local, no qual haverá uma identificação maior do público com o emissor da mensagem.

Porém, é de suma importância que a utilização do video seja vinculada a uma proposta pedagógica consciente das exigências de uma educação transformadora que priorize a criatividade, a pesquisa e a formaçáo para a cidadania. Moran (1994) complementa afirmando que o vídeo educacional não deve simplesmente reproduzir conteúdos, mas deve favorecer a produção de novas formas de interação entre o conteúdo, os alunos e o ambiente ao qual o mesmo se insere.

\section{Referências}

BELLONI, M, L. Educaçáo a distância/ Maria Luiza Belloni. 4 edição Campinas, SP: Autores associados, 2006 (coleção educação contemporânea).

BRANDÃO, C. R. O que é Educação. 6. Ed. São Paulo: Ática, 1982.

BRASIL, Secretaria de Educação Fundamental. Parâmetros Curriculares Nacionais: Ciências naturais. Terceiro e quarto ciclos. Brasília. MEC/SEF, 1998.

BRASIL. Lei de Diretrizes e Bases. Disponível em: http//www.mec.gov.br/legis/pdf/lei9394. pdf.

CARDOSO NETO, C. Tecnologia para EAD: videoconferência. Disponível em: <http:// www.cciencia.ufrj.br/educnet/videconf.htm>. Acesso em: 07 jun. 2012.

CARNEIRO, M.L.F. Videoconferência: Ambiente para educação à distância. In: Workshop Informática na Educação - PGIE/UFRGS. Porto Alegre, 1999. Disponível em: <http://penta. ufrgs.br/pgie/workshop/mara.htm>. Acesso em: 17 jun. 2012.

CASTELLS, M. A sociedade em rede. São Paulo: Paz e Terra, 1999.

CRUZ, D.M. e MORAES, M. Manual de videoconferência. Florianópolis. Laboratório de Ensino a Distância. UFSC, 1998.

DELIZOICOV D.; ANGOTI, J. A. P. PERNAMBUCO, M.M. Ensino de Ciências: fundamentos e métodos. 1. ed. São Paulo:Cortez,2003.

DEMO, Pedro. (1985). Ciências Sociais e Qualidade. São Paulo: Artmed, 96-110.

FISCHER, G. S. Um ambiente virtual multimídia de ensino na WEB, com transmissáo ao vivo e interatividade. 2000. Dissertação (Mestrado em Informática) - Universidade Federal do Rio Grande do Sul, Porto Alegre.

FRANCO, M.L. O Livro Didático de História no Brasil: a versão fabricada. São Paulo: Global, 1982. 
LETWIN, E. (org.) Tecnologia Educacional $₫$ política, histórias e propostas. Porto Alegre: Artes Médicas, 1997, p23-79.

LOPES, A.O. Aula expositiva: Superando o Tradicional. In VEIGA, I.P.A. (Org). Técnicas de Ensino: Por Que Não? 12 ed. Campinas: Papirus, 2001.

MORAN, M, J. Ensino e Aprendizagem inovadores com tecnologias. Revista Informática na Educação: Teoria \& Prática. Porto Alegre - RS. 2000.

MORAN, M, J. O Vídeo na Sala de Aula. Texto publicado na Revista Comunicação \& Educação. São Paulo, ECA-Ed. Moderna. 1995. Disponível em:<http://www.eca.usp.br/prof/ moran/vidsal.htm>. Acesso em 20 jun. 2012. 1995 -b.

OLIVEIRA, J. C. TVS: um sistema de videoconferência. 1996. Dissertação (Mestrado) PUC-RJ, Rio de Janeiro.

PRADO, M.E.B.B. VALENTE, J.A.A. Educação à distância possibilidade a formaçáo do professor com base no ciclo da prática pedagógica. in: MORAES.M.C. Educação a distância: fundamentos e práticas. Campinas: Unicamp/NIED, 2002.

RODRIGUES, N. Da Mistificação da escola a Escola necessária. 2. ed. São Paulo, Cortez,1998.

SACERDOTE, H.C.S. Análise do vídeo como recurso tecnológico educacional. REVELLI - Revista de Educação, Linguagem e Literatura da UEG. v. 2, n. 1, março de 2010. 